\title{
Prestress effect on the thermomechanical response and fatigue life prediction of viscoelastic plates
}

\author{
Zhuk Ya. O., Ostos O. Kh., Pyatetskaya O. V. \\ Taras Shevchenko National University of Kyiv, \\ 64 Volodymyrska Str., 01601, Kyiv, Ukraine
}

(Received 29 November 2019; Accepted 9 March 2020)

\begin{abstract}
A statement of the coupled thermomechanical problem on forced resonant vibrations and dissipative heating of hinged viscoelastic elastomeric rectangular plate is given with account of prestresses applied. The statement is based on the standard Kirchhoff-Love hypotheses and concept of complex characteristics that are used to describe the viscoelastic material response to harmonic loading. Both steady-state and transient thermal response is investigated. Influence of the prestress is studied in details for both uniaxial and biaxial preliminary stresses applied. Dissipative heating temperature histories are calculated for the variety of the prestress and loading parameters. Temperature criterion is adopted to determine the critical state. The data obtained are used for the plate fatigue life prediction and the prestress effect on the plate response.
\end{abstract}

Keywords: thermomechanical coupling, viscoelastic plate, cyclic loading, prestress, dissipative heating.

2010 MSC: $74,74 \mathrm{~F}, 74 \mathrm{D}, 74 \mathrm{~F} 05$

DOI: $10.23939 / \mathrm{mmc} 2020.01 .112$

\section{Introduction}

Mechanical engineering equipment, aerospace industry and energy generation machinery as well as transport engine/structure components can be subjected to severe mechanical and thermal cyclic loads. A prime design objective of these components is to assure the safe life of these components under such loading environment. Assessment of component life depends on the behavior of materials used. Polymers are widely used as materials for the structural components mentioned. Under intensive cyclic loading, the effect of dissipative heating can be particularly profound for the polymers. It is one of the most dangerous phenomena that occur under cyclic loading of structural members made of polymers or polymer matrix composites being subjected to intensive high-magnitude vibrations. The dissipative heating is caused by an appearance of a mechanical hysteresis resulting from the viscoelastic nature of the most of industrial polymers. Part of the dissipated mechanical energy leads to generation of thermal energy [1-4], while the rest of the energy transferred to the structure is both partly stored in the material [5] and dissipated as a result of plastic deformation [6,7], viscoplastic deformation, and variations of yield limit caused by isotropic and kinematic hardening [8].

It is generally adopted that dissipative heating is usually attributed to the internal friction of the material [9], which causes the hysteretic response. Energy dissipated as a heat leads to the increase of the temperature of the loaded structure. Small temperature advance over one separate cycle can result in high heating level for prolonged operational period. For polymeric materials, the situation worsens by the low thermal conductivity of most of the structural polymers, especially thermoplastics [10], that leads to high temperature localization and exceeding the glass transition temperature of a polymer $[9$, 10].

The effect of thermomechanical coupling described above should be taken account for when the adequate models for fatigue life predictions are developed. This implies a necessity for the deep investigation of dissipative heating, including its physical nature, the consequences, and the relations with degradation mechanisms in structural elements, as well as the estimation of safe temperature ranges. 
Additional factor that can significantly influence the fatigue life prediction of the polymeric structures is the residual stress which can arise as a result of manufacturing processes. For the subsequent cyclic loading problem, these stresses should be considered as prestresses. The effect of the prestresses, as well, have to be taken into account to improve the reliability of the fatigue life prediction technique.

To address the issue of fatigue life prediction with account of thermomechanical coupling, the theories based on the relations between the amplitudes of main field variables are usually used to describe the thermomechanical response of viscoelstic solids under cyclic loading. Application of complex amplitudes and complex moduli concept in the case of harmonic loading yields the complete system of amplitude equations for linearized coupled thermoviscoelasticity in terms of complex amplitudes. This system is complemented with the complex analogues of the equation of motion along with the stationary or non-stationary equation of heat transfer. In the former case, the temperature-frequency characteristics of vibration can be obtained and the critical loading parameters can be specified. To describe the overcritical heating and, therefore, to build the thermal fatigue $S-N$ curves the latter equation should be used instead. The detailed reviews of the theories and approaches developed along with the numerous applications can be found in [12-17].

In this paper, a fatigue model for prediction of a number of cycles to thermal failure is developed, taking into consideration stationary dissipative heating and structure prestress that can significantly affect the fatigue life characteristics of the viscous rectangular plate subjected to transverse harmonic loading. Special attention is paid to the influence of membrane prestress on the amplitude-frequency and temperature-frequency characteristics as well as on the non-stationary histories of dissipative heating for cyclically excited plate.

\section{Problem statement. Main equations}

Let us consider a hingedly supported plate of thickness $h$ with planform dimensions $a$ and $b$. It is assumed that the plate is composed of the linear viscoelastic material which material properties are frequency, amplitude and temperature independent. The rectangular Cartesian coordinates $(x, y, z)$ with the $x y$-plane coinciding with the geometric middle plane of the plate and the $z$-coordinate taken positive upward is introduced. The plate contour is formed by the edges $x=0, a ; y=0, b$. It is also assumed that prestresses are generated in the plate as a result of manufacturing process. The prestresses are simulated by the presence of normal membrane forces $N_{x x}, N_{y y}$ and, in general case, by shear membrane force $N_{x y}$. The plate is subjected to transverse loading $q_{z}=q_{0}^{\prime}(x, y) \cos \omega t-q_{0}^{\prime \prime}(x, y) \sin \omega t$ that is distributed over the plate surface according to specific law and is harmonically varying in time $t$ with amplitude $q_{0}(x, y)=\left(q_{0}^{\prime}(x, y)^{2}+q_{0}^{\prime \prime}(x, y)^{2}\right)^{1 / 2}$ and frequency $\omega$ which is close to one of the resonances.

The plate edges are assumed to be thermally insulated while the convective heat transfer to the ambient of temperature $T_{C}$ is supposed to take place at the face surfaces of the plate.

To simulate the mechanical response of the plate under consideration, the classical Kirchhoff-Love hypotheses are made use of $[18,19]$. The integral operators of linear viscoelasticity are used to describe the viscoelastic properties of the plate material [12-14]. In the particular case of harmonic deformation, these operators are reduced to multiplication of complex quantities $\tilde{a} * \tilde{b}=\left(a^{\prime}+i a^{\prime \prime}\right)\left(b^{\prime}+i b^{\prime \prime}\right)$ where the operator and complex quantities are marked with asterisk and wave respectively. It is also assumed that temperature is constant through the plate thickness.

In general case, the equations of transverse vibration of the plate are obtained in the following form $[18,19]$

$$
\begin{aligned}
& \frac{\partial N_{x x}}{\partial x}+\frac{\partial N_{x y}}{\partial y}=J_{0} \frac{\partial^{2} u}{\partial t^{2}} \\
& \frac{\partial N_{x y}}{\partial x}+\frac{\partial N_{y y}}{\partial y}=J_{0} \frac{\partial^{2} v}{\partial t^{2}}
\end{aligned}
$$

Mathematical Modeling and Computing, Vol. 7, No.1, pp.112-124 (2020) 


$$
\frac{\partial^{2} M_{x x}}{\partial x^{2}}+2 \frac{\partial^{2} M_{x y}}{\partial x \partial y}+\frac{\partial^{2} M_{y y}}{\partial y^{2}}+N(u, v, w)-k w+q(x, y, t)=J_{0} \frac{\partial^{2} w}{\partial t^{2}}-J_{2} \frac{\partial^{2}}{\partial t^{2}}\left(\frac{\partial^{2} w}{\partial x^{2}}+\frac{\partial^{2} w}{\partial y^{2}}\right),
$$

where $u, v$ and $w$ are components of the displacement field along $O x, O y$ and $O z$ axis respectively; $N_{i j}$ and $M_{i j}, i, j=x, y$ are thickness-integrated forces and moments, known as the stress resultants [18,19];

$$
N(u, v, w)=\frac{\partial}{\partial x}\left(N_{x x} \frac{\partial w}{\partial x}+N_{x y} \frac{\partial w}{\partial y}\right)+\frac{\partial}{\partial y}\left(N_{x y} \frac{\partial w}{\partial x}+N_{y y} \frac{\partial w}{\partial y}\right),
$$

$k$ is the foundation modulus (for the cases where it have to be taken account for), $\rho$ is the material density.

In system (1), $J_{0}$ and $J_{2}$ are the mass moments of inertia $J_{0}=\int_{-\frac{h}{2}}^{\frac{h}{2}} \rho d z, J_{2}=\int_{-\frac{h}{2}}^{\frac{h}{2}} \rho z^{2} d z$, and the term with $J_{2}$ should be preserved if the rotary inertia effects are of particular interest.

As the Kirchhoff-Love hypotheses are considered to be valid so the membrane and bending stresses are appeared to be uncoupled. It is also assumed the prestresses induced are constant $\left(N_{x x}=N_{x x}^{0}=\right.$ const, $N_{y y}=N_{y y}^{0}=$ const, $N_{x y}=N_{x y}^{0}=$ const). Under these assumptions, the in-plane problem for the plate becomes statically determinate. Thus, the first and second equations from (1) are satisfied identically.

Classical plate theory formalism for isotropic elastic material yields the 3rd equation from (1) in the form

$$
-D\left(\frac{\partial^{4} w}{\partial x^{4}}+2 \frac{\partial^{4} w}{\partial x^{2} \partial y^{2}}+\frac{\partial^{4} w}{\partial y^{4}}\right)+N(u, v, w)+q(x, y, t)=J_{0} \frac{\partial^{2} w}{\partial t^{2}}
$$

or

$$
D \nabla^{4} w+\rho h \frac{\partial^{2} w}{\partial t^{2}}=N_{x x}^{0} \frac{\partial^{2} w}{\partial x^{2}}+2 N_{x y}^{0} \frac{\partial^{2} w}{\partial x \partial y}+N_{y y}^{0} \frac{\partial^{2} w}{\partial y^{2}}+q(x, y, t),
$$

where $D=E h^{3} / 12\left(1-\nu^{2}\right)$ is the plate bending stiffness coefficient, $E$ and $\nu$ are the material Young's modulus and Poisson ratio respectively; $\nabla^{4}=\frac{\partial^{4}}{\partial x^{4}}+2 \frac{\partial^{4}}{\partial x^{2} \partial y^{2}}+\frac{\partial^{4}}{\partial y^{4}}$.

As a result, in the case of temperature independent material properties and assumption of a temperature constancy through the plate thickness, the mechanical problem is reduced to two uncoupled problems: (i) plane stress problem, (ii) pure bending problem. The former one defines the prestress while the latter problem describes the varying harmonically in time pure bending state which is superimposed over the prestressed state of the plate.

Boundary conditions for the linear bending of a rectangular plate with edges parallel to the $x$ and $y$ coordinates for the particular case of hingedly supported have the form

$$
\begin{aligned}
& w=0, \quad \frac{\partial^{2} w}{\partial x^{2}}=0 \quad \text { at } \quad x=0, a ; \\
& w=0, \quad \frac{\partial^{2} w}{\partial y^{2}}=0 \quad \text { at } \quad y=0, b .
\end{aligned}
$$

Under harmonic loading, investigation of steady-state vibration regime is usually performed with the use of complex moduli and complex amplitudes concept [12-15]. These yields the equation (7) as follows

$$
\tilde{D} \nabla^{4} \tilde{w}+\rho h \omega^{2} \frac{\partial^{2} \tilde{w}}{\partial t^{2}}=N_{x x}^{0} \frac{\partial^{2} \tilde{w}}{\partial x^{2}}+2 N_{x y}^{0} \frac{\partial^{2} \tilde{w}}{\partial x \partial y}+N_{y y}^{0} \frac{\partial^{2} \tilde{w}}{\partial y^{2}}+\tilde{q}(x, y),
$$

where $\tilde{D}=D^{\prime}+i D^{\prime \prime}, \tilde{w}(x, y)=w^{\prime}(x, y)+i w^{\prime \prime}(x, y)$ and $\tilde{q}(x, y)=q^{\prime}(x, y)+i q^{\prime \prime}(x, y)$ are complex bending stiffness coefficient, deflection of the plate and load; $i=\sqrt{-1}$. It is worth mentioning here that expressions for the boundary conditions should have the same form (3) with substitution of complex variable $\tilde{w}$ instead of real one $w$.

To obtain the time variation laws for the beam deflection and load, one should apply the formulas

$$
\begin{gathered}
w(x, y, t)=w^{\prime}(x, y) \cos \omega t-w^{\prime \prime}(x, y) \sin \omega t, \\
q(x, y, t)=q^{\prime}(x, y) \cos \omega t-q^{\prime \prime}(x, y) \sin \omega t
\end{gathered}
$$


Here $(\cdot)^{\prime}$ and $(\cdot)^{\prime \prime}$ are the real and imaginary parts of the complex amplitude.

The complex equation (4) is equivalent to system of two real equations with respect to the complex amplitudes in the form

$$
\left\{\begin{array}{c}
D^{\prime} \nabla^{4} w^{\prime}-D^{\prime \prime} \nabla^{4} w^{\prime \prime}-\rho h \omega^{2} w^{\prime}=N_{x x}^{0} \frac{\partial^{2} w^{\prime}}{\partial x^{2}}+2 N_{x y}^{0} \frac{\partial^{2} w^{\prime}}{\partial x \partial y}+N_{y y}^{0} \frac{\partial^{2} w^{\prime}}{\partial y^{2}}+q^{\prime}, \\
D^{\prime} \nabla^{4} w^{\prime \prime}+D^{\prime \prime} \nabla^{4} w^{\prime}-\rho h \omega^{2} w^{\prime \prime}=N_{x x}^{0} \frac{\partial^{2} w^{\prime \prime}}{\partial x^{2}}+2 N_{x y}^{0} \frac{\partial^{2} w^{\prime \prime}}{\partial x \partial y}+N_{y y}^{0} \frac{\partial^{2} w^{\prime \prime}}{\partial y^{2}}+q^{\prime \prime}
\end{array}\right.
$$

with the boundary conditions (3) rewritten in terms of the complex amplitudes as well

$$
\begin{array}{llll}
w^{\prime}=w^{\prime \prime}=0, & \frac{\partial^{2} w^{\prime}}{\partial x^{2}}=\frac{\partial^{2} w^{\prime \prime}}{\partial x^{2}}=0 \quad \text { at } & x=0, a \\
w^{\prime}=w^{\prime \prime}=0, & \frac{\partial^{2} w^{\prime}}{\partial y^{2}}=\frac{\partial^{2} w^{\prime \prime}}{\partial y^{2}}=0 & \text { at } & y=0, b .
\end{array}
$$

Evolution of the temperature field is described by the heat conduction equation averaged over the plate thickness and vibration period

$$
\rho \operatorname{ch} \frac{\partial \theta}{\partial t}=\lambda h\left(\frac{\partial^{2} \theta}{\partial x^{2}}+\frac{\partial^{2} \theta}{\partial y^{2}}\right)-2 \alpha_{S} \theta+\left\langle\bar{W}_{D}\right\rangle ;
$$

complemented with thermal initial and boundary conditions

$$
\begin{array}{rlrl}
\theta & =0 \quad \text { at } & t=0 ; \\
\frac{\partial \theta}{\partial x} & =0 \quad \text { at } & x=0, a ; \\
\frac{\partial \theta}{\partial y} & =0 \quad \text { at } & y & =0, b .
\end{array}
$$

In the equations (7) and (8), $\theta$ is the dissipative heating temperature, $\theta=T-T_{C} ; c, \lambda$ and $\alpha_{S}$ are the specific heat, heat conductivity coefficient and heat transfer coefficient at the face surfaces of the plate respectively; $T_{C}$ is the ambient temperature; $\left\langle\bar{W}_{D}\right\rangle$ is the dissipative function averaged over the period of vibrations and over the plate thickness

$$
\left\langle\bar{W}_{D}\right\rangle=\frac{\omega}{2}\left[\left(M_{x x}^{\prime \prime} \varepsilon_{x x}^{1}{ }^{\prime}-M_{x x}^{\prime} \varepsilon_{x x}^{1}{ }^{\prime \prime}\right)+\left(M_{y y}^{\prime \prime} \varepsilon_{y y}^{1}{ }^{\prime}-M_{y y}^{\prime} \varepsilon_{y y}^{1}{ }^{\prime \prime}\right)+\left(M_{x y}^{\prime \prime} \gamma_{x y}^{1}{ }^{\prime}-M_{x y}^{\prime} \gamma_{x y}^{1}{ }^{\prime \prime}\right)\right]
$$

where

$$
\begin{aligned}
& \tilde{\varepsilon}_{x x}^{1}=\varepsilon_{x x}^{1}{ }^{\prime}+i \varepsilon_{x x}^{1 \prime \prime}=-\frac{\partial^{2} \tilde{w}}{\partial x^{2}}, \\
& \tilde{\varepsilon}_{y y}^{1}=\varepsilon_{y y}^{1}{ }^{\prime}+i \varepsilon_{y y}^{1}{ }^{\prime \prime}=-\frac{\partial^{2} \tilde{w}}{\partial y^{2}}, \\
& \tilde{\gamma}_{x y}^{1}=\gamma_{x y}^{1}{ }^{\prime}+i \gamma_{x y}^{1 \prime \prime}=-2 \frac{\partial^{2} \tilde{w}}{\partial x \partial y} ; \\
& \tilde{M}_{x x}=M_{x x}^{\prime}+i M_{x x}^{\prime \prime}=-\tilde{D}\left[\frac{\partial^{2} \tilde{w}}{\partial x^{2}}+\tilde{\nu} \frac{\partial^{2} \tilde{w}}{\partial y^{2}}\right] ; \\
& \tilde{M}_{y y}=M_{y y}^{\prime}+i M_{y y}^{\prime \prime}=-\tilde{D}\left[\tilde{\nu} \frac{\partial^{2} \tilde{w}}{\partial x^{2}}+\frac{\partial^{2} \tilde{w}}{\partial y^{2}}\right] ; \\
& \tilde{M}_{x y}=M_{x y}^{\prime}+i M_{x y}^{\prime \prime}=-\tilde{D}(1-\tilde{\nu}) \frac{\partial^{2} \tilde{w}}{\partial x \partial y} .
\end{aligned}
$$

In the expressions (10), the quantities $\tilde{M}_{i j}, \tilde{\varepsilon}_{i j}^{1}$ and $\tilde{\gamma}_{x y}^{1}, i, j=x, y$ are complex-value analogues of moments from equations (1) and bending strains (curvatures and twisting); $\tilde{\nu}$ is the complex Poisson ratio, $\tilde{\nu}=\nu^{\prime}-i \nu^{\prime \prime}$. Let us emphasize here that version of the cyclic viscoelasticity with real Poisson 
ratio and complex bulk modulus is chosen for the materials under consideration in this problem. Thus relations $\nu^{\prime}=\nu, \nu^{\prime \prime}=0$ are assumed to be valid further on.

As a result, a statement of the coupled thermomechanical problem on forced vibrations and dissipative heating of hinged viscoelastic plate with account of prestresses applied is given by the equations (5) and (7) with the expression (9) for the dissipative function complemented with correspondent mechanical boundary conditions (6) along with thermal initial and boundary conditions (8).

\section{Solution technique}

Let us study the case when the prestress state can be a result of presence of the normal preliminary tractions only: $N_{x x}^{0}=$ const $\neq 0, N_{y y}^{0}=$ const $\neq 0, N_{x y}^{0}=0$.

It is worth mentioning here that for cyclically stable materials, mechanical processes stabilize much faster than the thermal ones [12]. It enables us to consider mechanical part of the problem as the steady-state process in contrast to the thermal part which is studied in the frame of transient analysis at the aforementioned assumptions with respect to the material constants. Thus, solution of the steady state vibration problem for the hingedly supported plate can be written in the form $[12,19]$

$$
\begin{aligned}
& w^{\prime}(x, y)=\sum_{m, n=1}^{\infty} w_{m n}^{\prime} \sin \frac{m \pi x}{a} \sin \frac{n \pi y}{b} \\
& w^{\prime \prime}(x, y)=\sum_{m, n=1}^{\infty} w_{m n}^{\prime \prime} \sin \frac{m \pi x}{a} \sin \frac{n \pi y}{b},
\end{aligned}
$$

where $w_{m n}^{\prime}$ and $w_{m n}^{\prime \prime}$ are unknown complex amplitudes of the eigenmode $m n$ corresponding to the natural frequency $\omega_{m n}$. This frequency is determined by the well-known formula taking account for the prestresses $[12,19]$

$$
\omega_{m n}=\left\{\frac{1}{\rho h} D_{0}\left[\left(\frac{m \pi}{a}\right)^{2}+\left(\frac{n \pi}{b}\right)^{2}\right]^{2}+\left(\frac{m \pi}{a}\right)^{2} N_{x x}^{0}+\left(\frac{n \pi}{b}\right)^{2} N_{y y}^{0}\right\}^{1 / 2},
$$

where $D_{0}$ is the plate bending stiffness coefficient calculated for elastic response of the plate material. In the case of viscoelastic material, it should be calculated as $D_{0}^{2}=D^{\prime 2}+D^{\prime \prime 2}$.

Vibration of a plate in the vicinity of the resonance frequency $\omega \approx \omega_{m n}$ is under consideration in the present study. It is also assumed that the loading is distributed over the plate surface according to the law corresponding to this particular mode of vibration to facilitate the resonant vibration

$$
q(x, y, t)=q_{m n}^{0}{ }^{\prime} \sin \frac{m \pi x}{a} \sin \frac{n \pi y}{b} \cos \omega t-q_{m n}^{0}{ }^{\prime \prime} \sin \frac{m \pi x}{a} \sin \frac{n \pi y}{b} \sin \omega t .
$$

If the transverse loading varies according to sine or cosine law over the time then this relation can be modified in the obvious way.

In this case, the plate response will be formed by the resonating mode $m n$, and the sums in the expression (11) can be discarded. Substitution of the resultant into (10) with accounting for $N_{x y}^{0}=0$ yields the system of two linear algebraic equations with respect to $w_{m n}^{\prime}$ and $w_{m n}^{\prime \prime}$ of the following form

$$
\left\{\begin{array}{l}
w_{m n}^{\prime}\left[D^{\prime} A-p h \omega^{2}+B\right]-w_{m n}^{\prime \prime} D^{\prime \prime} A=q_{m n}^{\prime}, \\
w_{m n}^{\prime} D^{\prime \prime} A+w_{m n}^{\prime \prime}\left[D^{\prime} A-p h \omega^{2}+B\right]=q_{m n}^{\prime \prime},
\end{array}\right.
$$

where $A=k_{x}^{4}+2 k_{x}^{2} k_{y}^{2}+k_{y}^{4}, B=N_{x x}^{0} k_{x}^{2}+N_{y y}^{0} k_{y}^{2} ; k_{x}=m \pi x / a, k_{y}=n \pi x / b$.

Solution of the equation (13) is determined by the expression 


$$
\begin{gathered}
w_{m n}^{\prime}=\Delta_{1} / \Delta, \quad w_{m n}^{\prime \prime}=\Delta_{2} / \Delta ; \\
\Delta_{1}=q_{m n}^{\prime}\left[D^{\prime}\left(k_{x}^{4}+2 k_{x}^{2} k_{y}^{2}+k_{y}^{4}\right)-\rho h \omega^{2}+\left(N_{x x}^{0} k_{x}^{2}+N_{y y}^{0} k_{y}^{2}\right)\right]+q_{m n}^{\prime \prime} D^{\prime \prime}\left(k_{x}^{4}+2 k_{x}^{2} k_{y}^{2}+k_{y}^{4}\right), \\
\Delta_{2}=q_{m n}^{\prime \prime}\left[D^{\prime}\left(k_{x}^{4}+2 k_{x}^{2} k_{y}^{2}+k_{y}^{4}\right)-\rho h \omega^{2}+\left(N_{x x}^{0} k_{x}^{2}+N_{y y}^{0} k_{y}^{2}\right)\right]-q_{m n}^{\prime} D^{\prime \prime}\left(k_{x}^{4}+2 k_{x}^{2} k_{y}^{2}+k_{y}^{4}\right), \\
\Delta=\left[D^{\prime}\left(k_{x}^{4}+2 k_{x}^{2} k_{y}^{2}+k_{y}^{4}\right)-\rho h \omega^{2}+\left(N_{x x}^{0} k_{x}^{2}+N_{y y}^{0} k_{y}^{2}\right)\right]^{2}+\left[D^{\prime \prime}\left(k_{x}^{4}+2 k_{x}^{2} k_{y}^{2}+k_{y}^{4}\right)\right]^{2} .
\end{gathered}
$$

To address the transient heat conductivity equation, one should define the expression for dissipative function $\left\langle\bar{W}_{D}\right\rangle$ from (7) as a function of the complex amplitudes of deflection. With making use of the expressions (10), the relations between moment and deflection amplitudes can be derived as follows

$$
\begin{gathered}
M_{x x}^{\prime}=-D^{\prime}\left[\frac{\partial^{2} w_{m n}^{\prime}}{\partial x^{2}}+\nu \frac{\partial^{2} w_{m n}^{\prime}}{\partial y^{2}}\right]+D^{\prime \prime}\left[\frac{\partial^{2} w_{m n}^{\prime \prime}}{\partial x^{2}}+\nu \frac{\partial^{2} w_{m n}^{\prime \prime}}{\partial y^{2}}\right] ; \\
M_{x x}^{\prime \prime}=-D^{\prime \prime}\left[\frac{\partial^{2} w_{m n}^{\prime}}{\partial x^{2}}+\nu \frac{\partial^{2} w_{m n}^{\prime}}{\partial y^{2}}\right]-D^{\prime}\left[\frac{\partial^{2} w_{m n}^{\prime \prime}}{\partial x^{2}}+\nu \frac{\partial^{2} w_{m n}^{\prime \prime}}{\partial y^{2}}\right] ; \\
M_{y y}^{\prime}=-D^{\prime}\left[\frac{\partial^{2} w_{m n}^{\prime}}{\partial y^{2}}+\nu \frac{\partial^{2} w_{m n}^{\prime}}{\partial x^{2}}\right]+D^{\prime \prime}\left[\frac{\partial^{2} w_{m n}^{\prime \prime}}{\partial y^{2}}+\nu \frac{\partial^{2} w_{m n}^{\prime \prime}}{\partial x^{2}}\right] ; \\
M_{x x}^{\prime \prime}=-D^{\prime \prime}\left[\frac{\partial^{2} w_{m n}^{\prime}}{\partial y^{2}}+\nu \frac{\partial^{2} w_{m n}^{\prime}}{\partial x^{2}}\right]-D^{\prime}\left[\frac{\partial^{2} w_{m n}^{\prime \prime}}{\partial y^{2}}+\nu \frac{\partial^{2} w_{m n}^{\prime \prime}}{\partial x^{2}}\right] ; \\
M_{x y}^{\prime}=-(1-\nu)\left(D^{\prime} \frac{\partial^{2} w_{m n}^{\prime}}{\partial x \partial y}-D^{\prime \prime} \frac{\partial^{2} w_{m n}^{\prime \prime}}{\partial x \partial y}\right) ; \\
M_{x y}^{\prime \prime}=-(1-\nu)\left(D^{\prime \prime} \frac{\partial^{2} w_{m n}^{\prime}}{\partial x \partial y}+D^{\prime} \frac{\partial^{2} w_{m n}^{\prime \prime}}{\partial x \partial y}\right) .
\end{gathered}
$$

Substitution of (15) into (9) with accounting for the first line from (10) yields the expression for the dissipative function

$$
\begin{aligned}
\left\langle\bar{W}_{D}\right\rangle=\frac{\omega}{2} & D^{\prime \prime}\left\{\left(\frac{\partial^{2} w_{m n}^{\prime}}{\partial x^{2}}\right)^{2}+\left(\frac{\partial^{2} w_{m n}^{\prime \prime}}{\partial x^{2}}\right)^{2}+\left(\frac{\partial^{2} w_{m n}^{\prime}}{\partial y^{2}}\right)^{2}+\left(\frac{\partial^{2} w_{m n}^{\prime \prime}}{\partial y^{2}}\right)^{2}+\right. \\
& \left.+2 \nu\left[\frac{\partial^{2} w_{m n}^{\prime}}{\partial x^{2}} \frac{\partial^{2} w_{m n}^{\prime}}{\partial y^{2}}+\frac{\partial^{2} w_{m n}^{\prime \prime}}{\partial x^{2}} \frac{\partial^{2} w_{m n}^{\prime \prime}}{\partial y^{2}}\right]+(1-\nu)\left[\left(\frac{\partial^{2} w_{m n}^{\prime}}{\partial x \partial y}\right)^{2}+\left(\frac{\partial^{2} w_{m n}^{\prime \prime}}{\partial x \partial y}\right)^{2}\right]\right\}
\end{aligned}
$$

The transient heat conductivity problem formed by the equation (7) complemented by the expression for the dissipative function (16) along with the thermal initial and boundary conditions (8) can be solved numerically.

\section{Numerical results and analysis}

Calculations were performed for both square and quadrilateral plates with the geometric parameters $a=0.1 \mathrm{~m}, b=0.1 \mathrm{~m}, h=0.005 \mathrm{~m}$ and $a=0.175 \mathrm{~m}, b=0.1 \mathrm{~m}, h=0.005 \mathrm{~m}$ respectively. Polyethylene was chosen as the plate material. Complex moduli for the material were taken from [20]: $E^{\prime}=$ $8.0 \cdot 10^{8} \mathrm{~Pa} ; E^{\prime \prime}=6.3 \cdot 10^{6} \mathrm{~Pa} ; \tan \theta=E^{\prime \prime} / E^{\prime}=0.0079$. Polyethylene Poisson ratio and density are chosen to be equal to $\nu=0.46$ and $\rho=953 \mathrm{~kg} / \mathrm{m}^{3}$ respectively. Thermal parameters for the problem were defined as follows: specific heat $c=2300 \mathrm{~W} / \mathrm{kg} \cdot{ }^{\circ} \mathrm{C}$, heat conductivity coefficient $\lambda=0.36 \mathrm{~W} / \mathrm{m} \cdot{ }^{\circ} \mathrm{C}$ and heat transfer coefficient at the face surfaces of the plate $\alpha_{S}=4 \mathrm{~W} / \mathrm{m}^{2} \cdot{ }^{\circ} \mathrm{C}$.

Harmonic loading of the plate with different preliminary normal membrane forces $N_{x x}$ and $N_{y y}$ was investigated. To describe the ratio between the tractions $N_{x x}$ and $N_{y y}$ in the case when both of them are present, a prestress coefficient $K_{f}=N_{x x} / N_{y y}$ was introduced.

The steady-state vibration problem is first to solve.

A natural frequency for the first eigenmode $(m=1, n=1)$ of the square plate for the prestress coefficient $K_{f}^{70}=10$ under a transverse loading with amplitude $q^{\prime}=600 \mathrm{~Pa}$ (with $q^{\prime \prime}=0$ ) is $f_{11}=$ 
472.2 Hz. Further on, the upper index $r$ in $K_{f}^{r}$ indicates a fixed value of the preliminary force $N_{y y}=$ $r \mathrm{~N} / \mathrm{m}$ with a variable value of $N_{x x}$. So, $K_{f}^{70}=10$ corresponds to the preliminary tractions $N_{x x}=$ $700 \mathrm{~N} / \mathrm{m}$ and $N_{y y}=70 \mathrm{~N} / \mathrm{m}$. If the coefficient $K_{f}^{70}=0$ then the case of $N_{x x}=70 \mathrm{~N} / \mathrm{m}$ and $N_{y y}=0$ is under consideration, simulating presence of the uniaxial prestress state only. Since the investigation was carried out in the vicinity of the first resonance, the spatial distributions as well as the deflection and temperature frequency characteristics were initially calculated near the fundamental frequency $f_{11}$, where $f_{m n}=\omega_{m n} / 2 \pi$ is the natural frequency corresponding to the first mode of vibration.

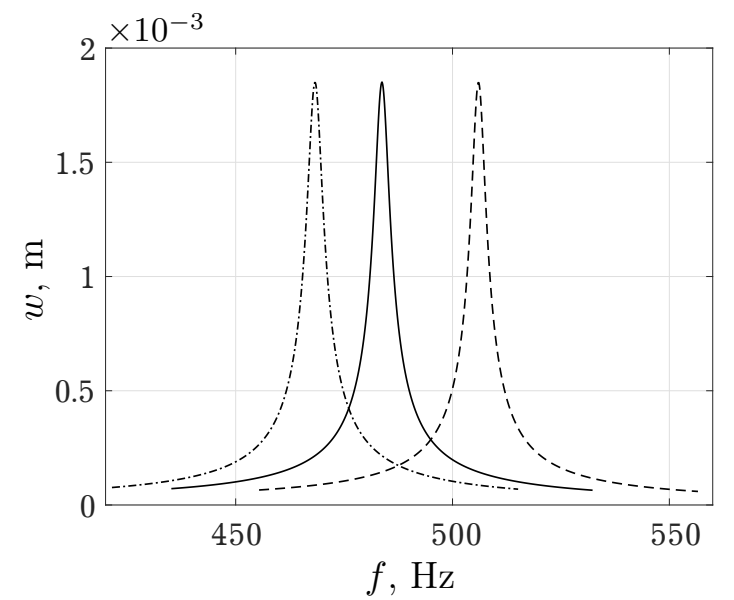

$a$

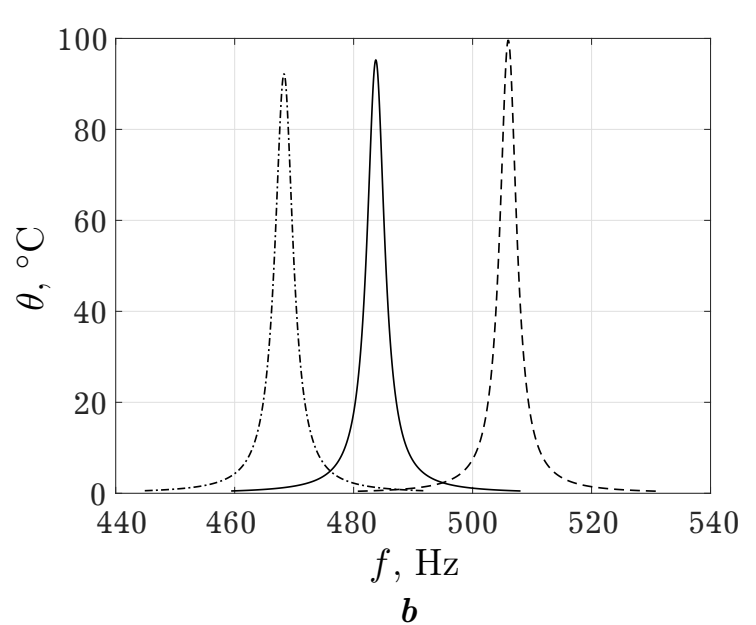

Fig. 1. Influence of the prestress level on the amplitude-frequency $(\boldsymbol{a})$ and temperature-frequency $(\boldsymbol{b})$ curves for the center point of the square plate.

The maximum deflection, $w_{\max }$, is achieved at the center point of the square plate $(x=a / 2$, $y=b / 2)$ and is equal to $1.8 \cdot 10^{-3} \mathrm{~m}$. The maximum heating temperature, $\theta_{\max }$, for the plate is also occurred at this point. The amplitude-frequency and temperature-frequency characteristics were calculated for the points of maximum values of the variables mentioned for the corresponding vibration modes.

In Fig. 1, the amplitude- and temperature-frequency curves of vibration at the point of maximum deflections and temperature in the vicinity of the first resonance frequency under a transverse loading with amplitude $q^{\prime}=600 \mathrm{~Pa}$ for different values of the coefficient $K_{f}^{70}$ are shown. The dash-dot, solid, and dashed lines there show the amplitude-frequency (Fig. 1a) and temperature-frequency (Fig. 1b) characteristics for the values of $K_{f}^{70}=0,40$, and 100 respectively.

Fig. $1 a$ illustrates the effect of shifting the resonant frequency (to the region of higher frequency values) with an increase in preliminary tensile membrane traction in the plate, which corresponds to the well-known theoretical and experimentally confirmed result. A similar effect is observed for the case of temperature-frequency curves (see Fig. 1b). The shift of the resonance region to the right is accompanied by an increase in temperature. The maximum value of the dissipative heating temperature reached under conditions described is $\theta_{\max }=99.6^{\circ} \mathrm{C}$.

In Fig. 2 the amplitude- and temperature-frequency curves for the square plate vibration in the vicinity of the first resonance frequency for $K_{f}^{70}=10$ are shown under different values of the transverse loading. In the figure dash-dot, solid, and dashed lines present the amplitude- and temperaturefrequency characteristics for the values of transverse loading with amplitude $q^{\prime}=350,500$, and $600 \mathrm{~Pa}$ respectively.

Analysis of the results presented in Fig. $2 a$ shows the behavior of the amplitude-frequency curves correspond to the typical behavior of the characteristics in the case of a linear viscoelastic material and is accompanied by an increase in the amplitude of deflection with an increase of the amplitude of transverse loading. Typical curve illustrating response of the sort mentioned is presented in Fig. $2 b$. The sharp increase in temperature at the resonance frequency occurs. This effect can be potentially 
dangerous because the dissipative heating temperature can reach the critical level causing the structure failure due to melting. For the curves shown, the maximum temperature calculated is equal to $\theta_{\max }=$ $92.97^{\circ} \mathrm{C}$. Respectively, the loading amplitude leading to the failure due to the thermal scenario can be called the critical load amplitude.
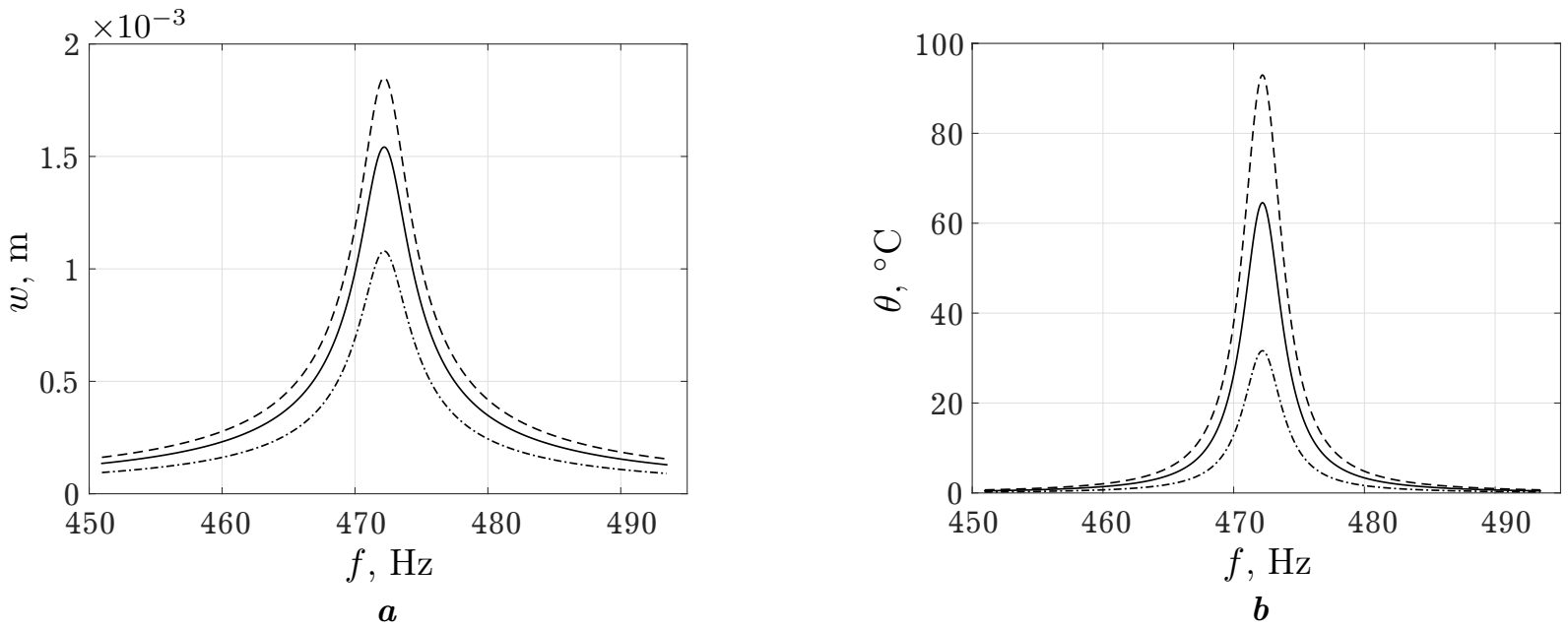

Fig. 2. Influence of the loading level on the amplitude-frequency $(\boldsymbol{a})$ and temperature-frequency $(\boldsymbol{b})$ characteristics.

For the elastomer chosen as the plate material, the melting point is $120^{\circ} \mathrm{C}$ approximately. Therefore, in this work, the value of $100^{\circ} \mathrm{C}$ was chosen as the critical value of the heating temperature $\theta_{c r}$ at which a noticeable softening of the material is observed.

Combining the results presented in Fig. 1 and Fig. 2, the influence of the initial stress for the each particular plate can be clarified and safe functioning regimes can be found for the loading amplitude applied.

It is worth mentioning here that a structure is usually able to work for some time under the load that exceeds the critical value. Under the overcritical loading amplitude, the life prediction for the structural elements demands the transient response of the structure to be studied. So, the nonstationary problem for the square plate is considered further on in the frame of the two-step procedure. At the first step, the mechanical part of the problem is solved as the steady-state problem and the dissipative function is determined with making use of the deflection amplitudes and loss modulus according to the formula (16). At the second step, the thermal part of the problem is solved in the frame of transient analysis.

Therefore, the second step comprises solution of the heat conduction equation (7) complemented with thermal initial and boundary conditions (8). Let us remind here that the equation $(7)$ is formulated in terms of the heating temperature $\theta=$ $T-T_{C}$. The ambient temperature is chosen to be equal to $T_{C}=20^{\circ} \mathrm{C}$.

In Fig. 3, the temperature-time dependence at the resonant frequency $f=506 \mathrm{~Hz}$ for the initial stresses described by the prestress coefficient $K_{f}^{70}=100$ under different values of the transverse loading amplitude is shown. Here the dashdot, solid, dashed, and dotted lines illustrate the dissipative heating temperature evolution for the values of transverse loading amplitudes $q^{\prime}=400$, 550,600 and $1000 \mathrm{~Pa}$ respectively.

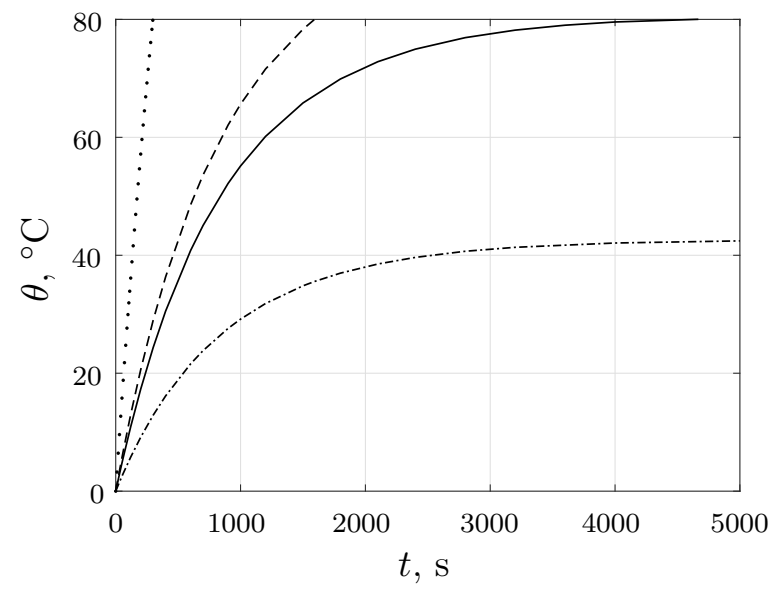

Fig. 3. Heating temperature evolution for different loading amplitudes at prestress coefficient $K_{f}^{70}=100$. 
To characterize the spatial distribution of the heating, the variation of the temperature along the line $y=b / 2$ for the square plate at the first $(f=506 \mathrm{~Hz})$ and second $(f=1186 \mathrm{~Hz})$ resonant frequencies for the prestress coefficient $K_{f}^{70}=100$ are shown in Fig. 4. The dash-dot, solid, dotted, and dashed lines present the heating temperature distributions for the values of transverse loading amplitudes $q^{\prime}=400,500,550$, and $600 \mathrm{~Pa}$ respectively.
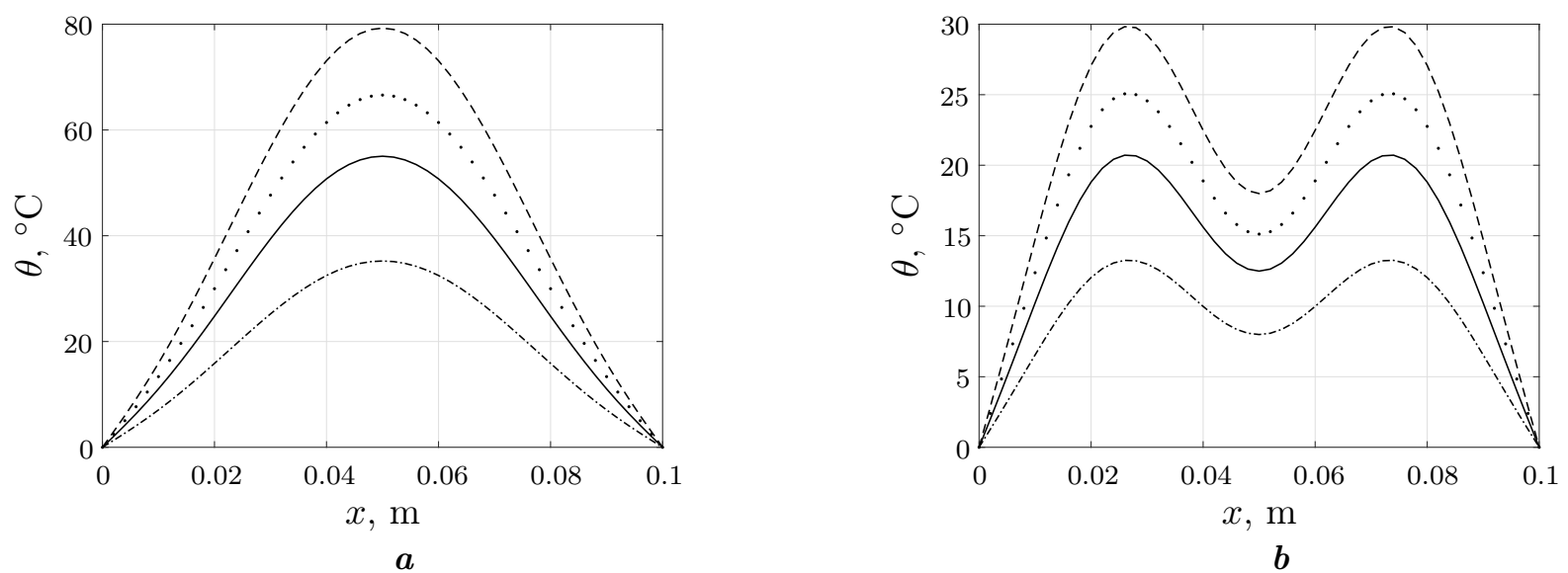

Fig. 4. Temperature distributions along the line $y=b / 2$ for the first $(\boldsymbol{a})$ and second $(\boldsymbol{b})$ eigenmodes.

Fig. $4 a$ illustrates the temperature distribution at the first resonance (eigenmode $m=1, n=1$ ). The maximum temperature is reached at $x=a / 2$ and equals $\theta_{\max }=79.3^{\circ} \mathrm{C}$. The same data for the second eigenmode $(m=1, n=2)$ are plotted in Fig. $4 b$. The maximum temperature in this case is reached at the points $x=a / 4$ and $x=3 a / 4$ and equals $\theta_{\max }=29.8^{\circ} \mathrm{C}$. Analysis of the figure evidently show that vibration at the first resonance is the most energy-intensive one.
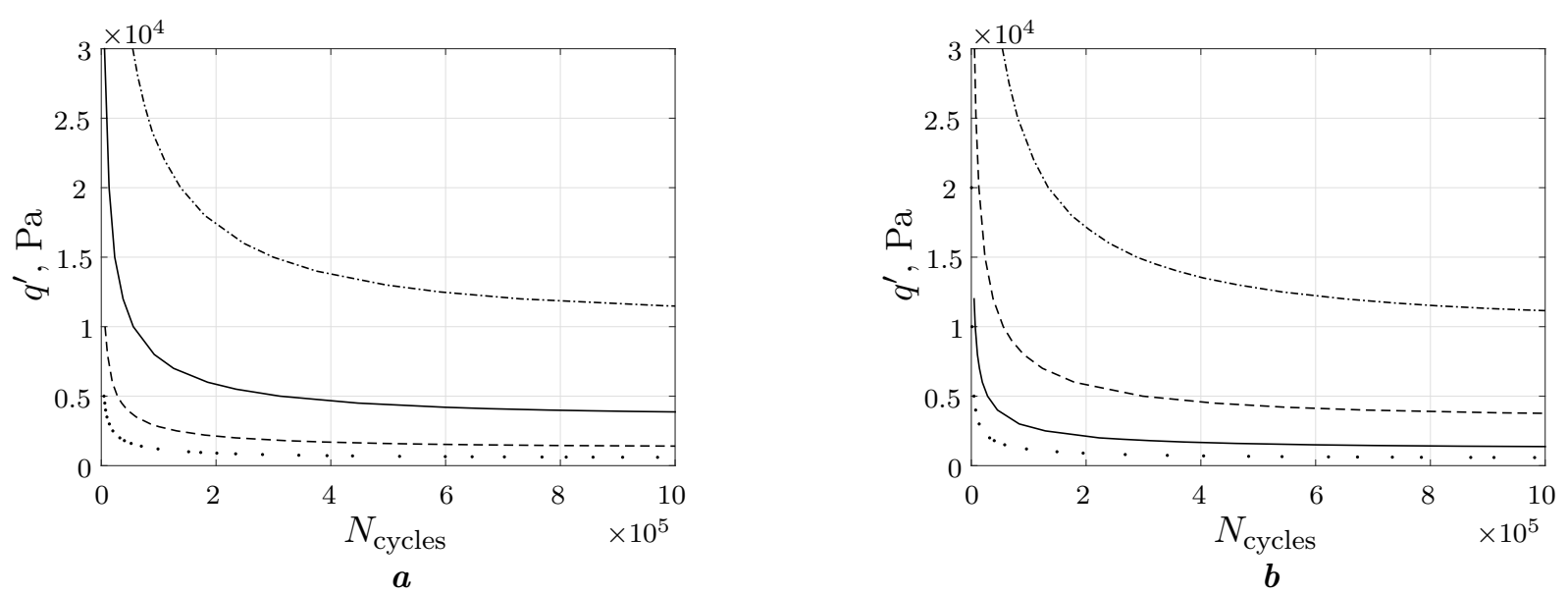

Fig. 5. $S-N$ curves for the square plate calculated at the rising $(\boldsymbol{a})$ and falling $(\boldsymbol{b})$ branches of the temperaturefrequency characteristics.

To estimate the working time interval for the structure under overcritical loading, the results simulating the temperature evolution which are presented in Fig. 3 can be used. The interval to thermal failure is determined by the time moment when the maximum heating temperature reaches the value of critical temperature level $\theta=80^{\circ} \mathrm{C}$ (the same as $T=100^{\circ} \mathrm{C}$ ) at any point of the structure. Obviously, these times correspond to the moments when temperature evolution curves intersect the line of critical temperature mentioned. If the curve does not intersect the line $\theta=80^{\circ} \mathrm{C}$ (see dash-dot line in Fig. 3) then the structure can work infinitely long and can fail due to mechanical scenario only. To predict the thermal fatigue life, the so called $S-N$ curves (or Wöhler diagrams) are usually used. In Fig. $5 a$ these diagrams are built for frequency $f=468.3 \mathrm{~Hz}$, which is resonant for the prestress coefficient $K_{f}^{70}=0$ (uniaxial prestress state with $N_{x x}=70 \mathrm{~N} / \mathrm{m}$ and $N_{y y}=0$ ). Here dotted, dashed, solid, and dash-dot lines correspond to $K_{f}^{70}=0,10,30$, and 90 respectively. All four curves in Fig. $5 a$ 
are obtained for the frequency $f=468.3 \mathrm{~Hz}$ (fixed frequency regime) that fall to the raising branch of the temperature-frequency characteristics. It should be noted here that Wöhler diagrams move to the region of higher values of loading amplitudes improving the durability of the structure caused by the shift of amplitude-frequency curve to the higher frequency region as the prestress level increases.

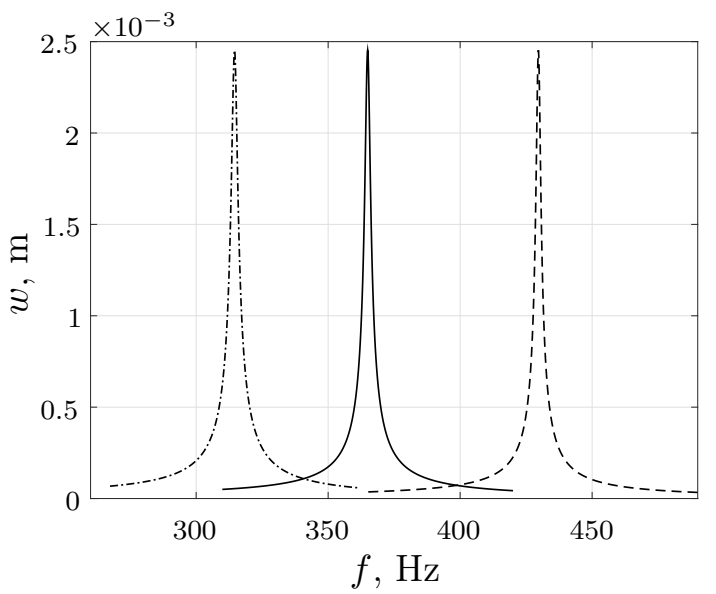

a

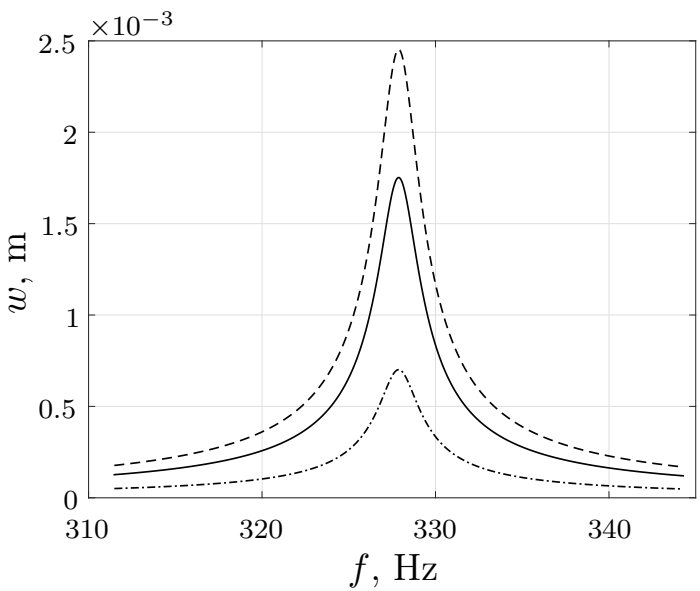

c

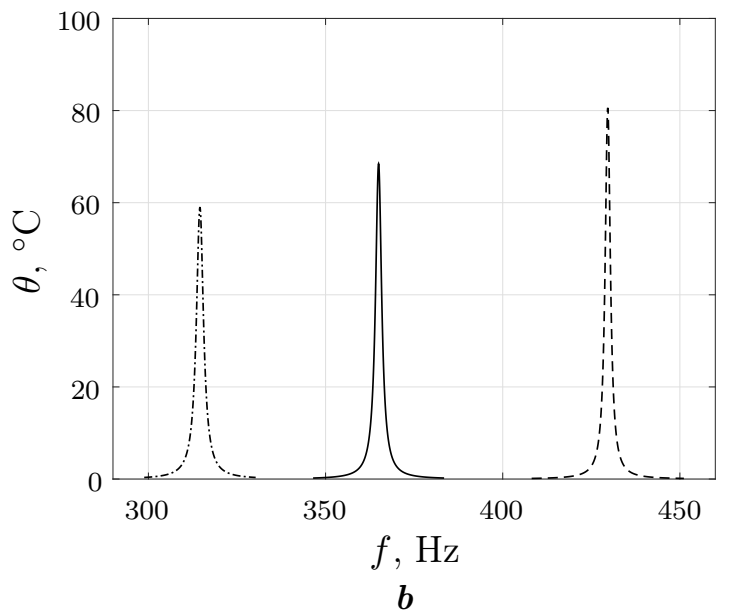

$b$

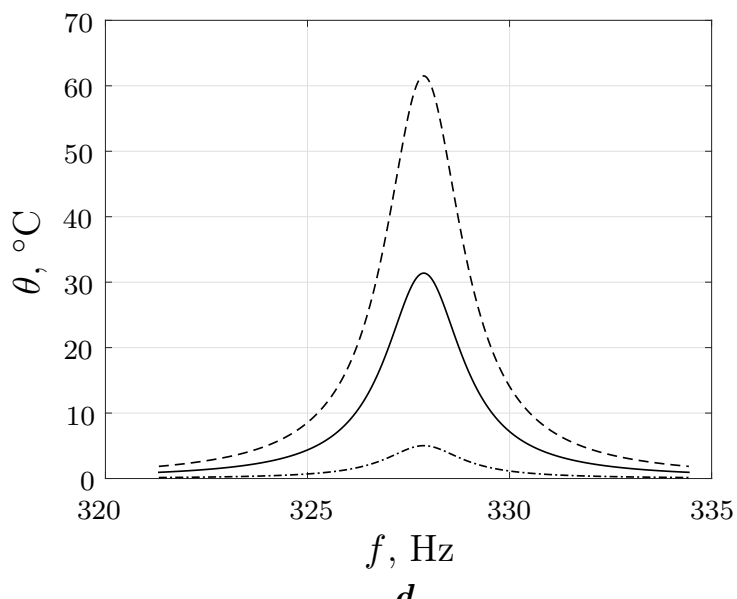

$d$

Fig. 6. Evolution of the radial stress distributions along the disk radius.

The analogous data for the case of falling branch of amplitude-frequency curve are shown in Fig. $5 b$. The calculation were performed for the frequency $f=506 \mathrm{~Hz}$, which is resonant for the coefficient $K_{f}^{70}=100$. In the figure, dotted, solid, dashed, and dash-dot lines correspond to $K_{f}^{70}=10,70,90$, and 100 respectively. The type of response shown in Fig. 5 corresponds to the effect of dynamics.

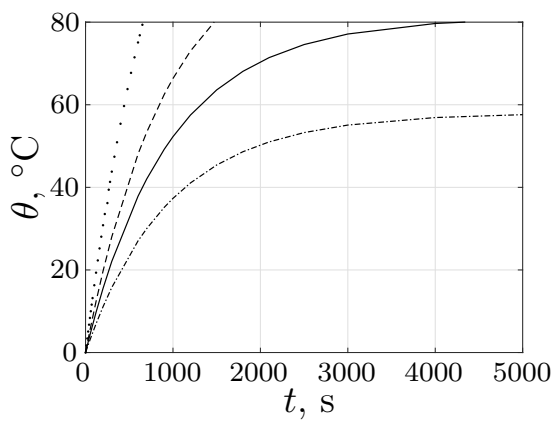

a

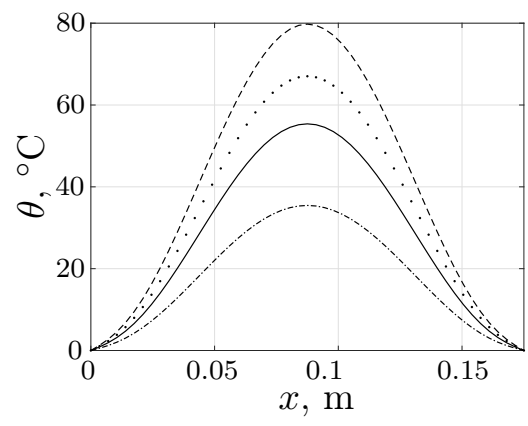

$b$

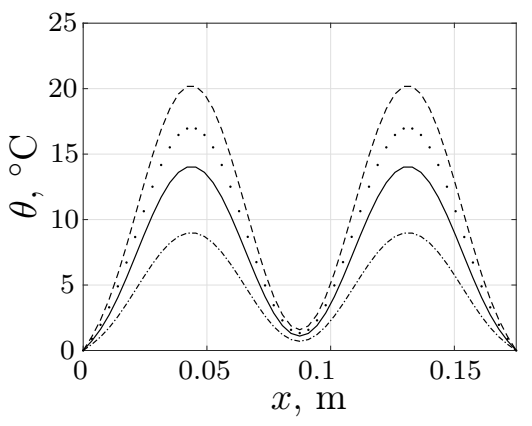

$c$

Fig. 7. Temperature evolution curves $(\boldsymbol{a})$, and temperature distributions along the line $y=b / 2$ for first (b) and second $(\boldsymbol{c})$ resonances for the rectangular plate. 
Both the stationary and non-stationary dissipative heating problem for the rectangular plate was solved as well.

In Fig. $6 a$ and $6 b$ the amplitude- and temperature-frequency curves for the point of maximum deflections and temperatures in the vicinity of the first resonance frequency under a transverse loading with amplitude $q^{\prime}=350 \mathrm{~Pa}$ for different values of the prestress coefficient $K_{f}^{500}$ are shown. Here the dash-dot, solid, and dashed lines illustrate the plate resonant response for the values of $K_{f}^{500}=0$, 40 , and 100 respectively. The maximum deflection reached is equal to $w_{\max }=2.5 \cdot 10^{-3} \mathrm{~m}$, while the highest value of the temperature equals $\theta_{\max }=80.6^{\circ} \mathrm{C}$.

In Fig. $6 c$ and $6 d$ the amplitude- and temperature-frequency characteristics of the rectangular plate vibration in the vicinity of the first resonance frequency for $K_{f}^{500}=10$ under different values of the transverse loading are depicted. Here the dash-dot, solid, and dashed lines show the amplitude- and temperature-frequency curves for $q^{\prime}=100,250$, and $350 \mathrm{~Pa}$ respectively. The maximum temperature reached is $\theta_{\max }=61.5^{\circ} \mathrm{C}$.

In Fig. $7 a$, the temperature evolution curves at the resonant frequency $f=429.6 \mathrm{~Hz}$ for the prestress coefficient $K_{f}^{500}=100$ under different values of the transverse loading are shown. The dash-dot, solid, dashed, and dotted lines correspond to loading amplitudes $q^{\prime}=300,355,400$ and $500 \mathrm{~Pa}$ respectively.

The distributions of the temperature in the rectangular plate along the line $y=b / 2$ at the resonant frequency $f=429.6 \mathrm{~Hz}$ (first resonance $m=1, n=1$ ) and $f=1059 \mathrm{~Hz}$ (second resonance $m=1$, $n=2$ ) for the prestress coefficient $K_{f}^{500}=100$ are shown in the Fig. $7 b$ and $7 c$. The dash-dot, solid, dotted, and dashed lines present the temperature variation for the loading amplitudes $q^{\prime}=300,355$, 400 and $500 \mathrm{~Pa}$ respectively. The highest temperature reached was 79.8 and $20.2^{\circ} \mathrm{C}$ respectively for the fist and second eigenmodes.

In the Fig. $8 a$, the Wöhler diagrams at frequency $f=314.5 \mathrm{~Hz}$ (the first resonance frequency of the rectangular plate under the prestress coefficient $K_{f}^{500}=0$ ) are shown for $K_{f}^{500}=0,10,20$, and 30 by the dotted, dashed, solid, and dash-dot lines respectively. This figure illustrates the thermal fatigue life prediction for the raising branch of temperature-frequency curve.
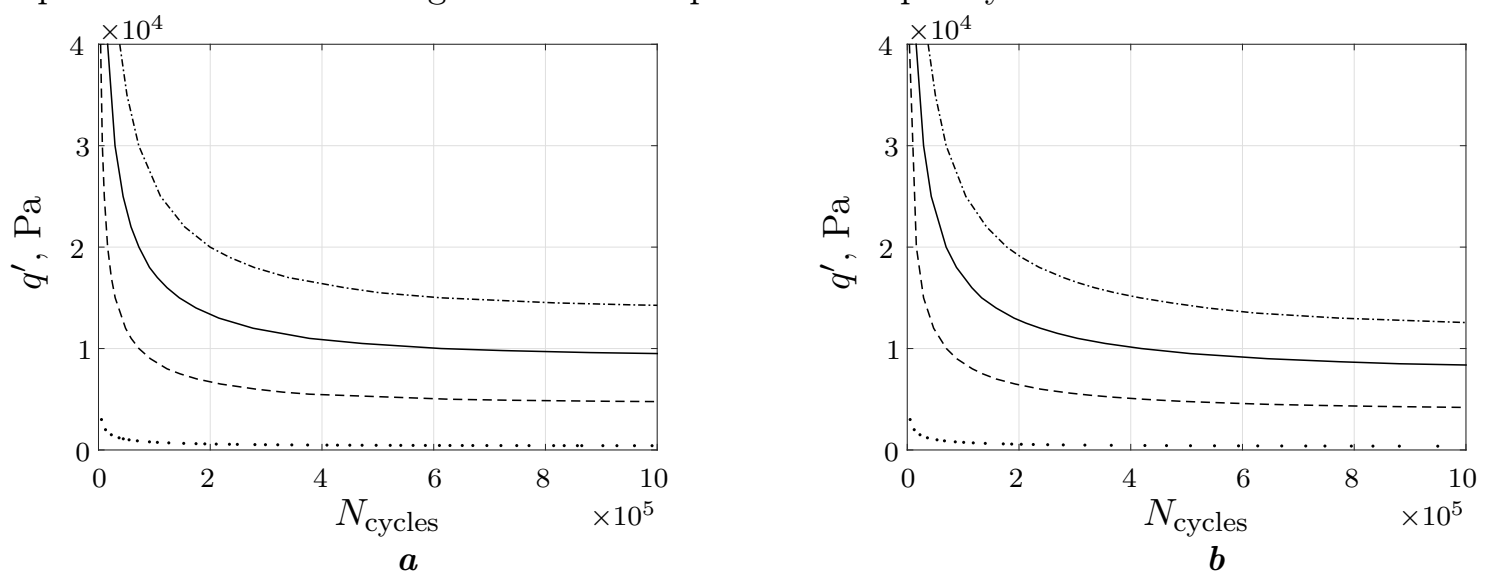

Fig. 8. Wöhler diagrams for the rectangular plate calculated at the rising $(\boldsymbol{a})$ and falling $(\boldsymbol{b})$ branches of the temperature-frequency characteristics.

The same estimation for the falling branch of the amplitude-frequency curve is shown in Fig. $8 b$. The data are calculated at the frequency $f=429.6 \mathrm{~Hz}$, which is resonance frequency for the prestress coefficient $K_{f}^{500}=100$. The dotted, dashed, solid, and dash-dot lines correspond to $K_{f}^{70}=70,80,90$, and 100 respectively.

In general, analysis of the results presented in Figs. $6-8$ shows qualitative agreement in response between square and rectangular plate. In both cases, to provide the safe and efficient functioning of the plate, it is necessary to avoid the vibration regimes that induce the high level of heating and prevent temperature of exceeding the critical value $\theta_{c r}$. With this respect, the accounting of prestresses can be crucial because these stresses can shift the amplitude-frequency curve either to or out the resonance region. 


\section{Conclusions}

This paper presents an investigation of the prestress influence on the thermomechanical response and fatigue life prediction of viscoelastic plates subjected to transverse harmonic loading. For the the Kirchhoff-Love hypotheses, the formulation and solution of the stationary and transient problems of forced resonant vibrations and dissipative heating of a viscoelastic elastomeric plate with preliminary normal membrane forces in cases of a square and rectangular plate, hinged along the contour are presented. Both steady-state and transient thermal response is investigated in details. For the most energy-intensive first mode of bending vibrations, the influence of the preliminary tensile stress state, as well as the level of the transverse distributed load on the amplitude-frequency characteristics and temperature evolution was studied. The critical values of prestresses and loading amplitudes are determined at which the heating temperature reaches the critical value that leads to the material softening. The thermal fatigue life curves for different levels of tensile both uniaxial and biaxial preliminary membrane stresses were built and analyzed. It was found that the effect of prestresses can be crucial because these stresses can shift the amplitude-frequency curve either to or out the resonance region.

[1] Steinberger R., Valadas Leitão T. I., Landstätter E., Pinter G., Billinger W., Lang R. W. Infrared thermographic techniques for non-destructive damage characterization of carbon fibre reinforced polymers during tensile fatigue testing. Int. J. Fatigue. 28 (10), 1340-1347 (2006).

[2] Rittel D. On the conversion of plastic work to heat during high strain rate deformation of glassy polymers. Mech. Mater. 31 (2), 131-139 (1999).

[3] Moissa S., Landsberg G., Rittel D., Halary J. L. Hysteretic thermal behavior of amorphous semi-aromatic polyamides. Polymer. 45 (25), 11870-11875 (2005).

[4] Mortazavian S., Fatemi A. Fatigue behavior and modeling of short fiber reinforced polymer composites: A literature review. Int. J. Fatigue. 70, 297-321 (2015).

[5] Haward R. N. Heating effects in the deformation of thermoplastics. Thermochim. Acta. 247 (1), 87-109 (1994).

[6] Hashemi M., Zhuk Y. The influence of strain amplitude, temperature and frequency on complex shear moduli of polymer materials under kinematic harmonic loading. Mech. Mech. Eng. 21, 157-170 (2017).

[7] Mehdizadeh M., Khonsari M. M. On the application of fracture fatigue entropy to variable frequency andloading amplitude. Theor. Appl. Fract. Mech. 98, 30-37 (2018).

[8] Krairi A., Doghri I. A thermodynamically-based constitutive model for thermoplastic polymers coupling viscoelasticity, viscoplasticity and ductile damage. Int. J. Plast. 60, 163-181 (2014).

[9] Katunin A., Fidali M. Fatigue and thermal failure of polymeric composites subjected to cyclic loading. Adv. Compos. Lett. 21 (3), 63-69 (2012).

[10] Mortazavian S., Fatemi A. Fatigue of short fiber thermoplastic composites: A review of recent experimental results and analysis. Int. J. Fatigue. 102, 171-183 (2017).

[11] Katunin A. Criticality of the Self-Heating Effect in Polymers and Polymer Matrix Composites during Fatigue, and Their Application in Non-Destructive Testing. Polymers. 11 (1), 19 (2019).

[12] Senchenkov I. K., Zhuk Ya. A., Karnaukhov V. G. Modeling the Thermomechanical Behavior of Physically Nonlinear Materials under Monoharmonic Loading. Int. Appl. Mech. 40 (9), 943-969 (2004).

[13] Zhuk Ya. A., Senchenkov I. K. On Linearization of the Stiffness Characteristics of Flexible Beams Made of Physically Nonlinear Materials. Int. Appl. Mech. 42 (2), 196-202 (2006).

[14] Zhuk Y. A., Senchenkov I. K. Monoharmonic approach to investigation of the vibrations and self-heating of thin-wall inelastic members. Journal of Civil Engineering and Management. 15 (1), 67-75 (2009).

[15] Karnaukhov V. G., Kirichok I. F. Forced Harmonic Vibrations and Dissipative Heating-up of Viscoelastic Thin-Walled Elements (Review). Int. Appl. Mech. 36 (2), 174-195 (2000).

[16] Hashemi M., Zhuk Y. A. The Influence of Temperature on the Cyclic Properties of the Transversely Isotropic Nanocomposite System Under Kinematic Harmonic Loading. J. Mat. Sci. 236 (2), 185-198 (2019).

Mathematical Modeling and Computing, Vol. 7, No.1, pp. 112-124 (2020) 
[17] Zhuk Y. A. Damping characteristics of three-layer beam-damper under harmonic loading. Math. Model. Comput. 1 (1), 109-119 (2014).

[18] Reddy J. N. Theory and Analysis of Elastic Plates and Shell. CRC Press (2006).

[19] Donnell L. H. Beams, Plates and Shells. McGraw-Hill (1976).

[20] Lazan B. Damping of materials and members in structural mechanics. Oxford etc., Pergamon Press (1968).

\title{
Вплив попередніх напружень на термомеханічну поведінку i втомну витривалість в'язкопружних пластин
}

\author{
Жук Я. О., Остос О. Х., П'ятецька О. В. \\ Київсъкий начіональний університет імені Тараса Шевченка, \\ вул. Володимирсъка, 64, 01601, Київ, Україна
}

\begin{abstract}
Розвинуто постановку зв'язаної задачі термомеханіки про вимушені резонансні коливання і дисипативний розігрів шарнірно опертої в'язкопружної еластомерної прямокутної пластини з врахуванням попередніх напружень. Постановка задачі грунтується на використанні гіпотез Кірхгофа-Лява і концепції комплексних модулів, які використані для описання реакції в'язкопружного матеріалу на гармонічне навантаження. Досліджено як стаціонарну, так і нестаціонарну температурну поведінку пластини. Детально вивчено вплив попереднього напруження як вздовж однієї, так і вздовж двох осей. Історії зміни температури дисипативного розігріву розраховано для різних значень попереднього напруження і параметрів навантаження. Для визначення критичного навантаження вибрано температурний критерій. Отримані дані використано для дослідження втомної витривалості пластини та впливу на неї попереднього напруження.
\end{abstract}

Ключові слова: термомеханічна зв'язаність, в'язкопружна пластина, ииклічне навантаження, попередні напруження, дисипативний розігрів. 